\title{
Evaluating Effect of Prophylactic Intravenous Dexamethasone in Post Spinal Shivering: A Single Centre Randomised Controlled Study
}

\author{
Chih NY, Voon B, Sayed Masri SNN, Mohamad Mahdi SN, Izaham A
}

Department of Anesthesiology and Intensive Care, Universiti Kebangsaan Malaysia Medical Center, Kuala Lumpur, Malaysia.

Keywords

post spinal shivering, pethidine, dexamethasone, central neuraxial anaesthesia.

\author{
Corresponding Author \\ Chih Nie Yeoh, \\ Dept. of Anesthesiology and Intensive Care, \\ Universiti Kebangsaan Malaysia Medical Center, \\ Jalan Yaacob Latif, Bandar Tun Razak, \\ 56000 Kuala Lumpur, Malaysia. \\ Tel : +60391455555 \\ E-mail: ychihnie@gmail.com \\ Received: 3 Nov 2020; Accepted: 18 August \\ 2021 \\ Doi: https://doi.org/10.31436/imjm.v20i4
}

\begin{abstract}
INTRODUCTION: Shivering is a common side effect of central neuraxial anaesthesia. Intravenous pethidine is commonly used in reducing shivering but has been associated with significant opioid side effects. Dexamethasone as a powerful anti-inflammatory and analgesia agent is postulated to inhibit inflammatory mediators' release thus inhibiting central thermoregulatory centre, potentially attenuating post spinal shivering. This double -blind randomised controlled study was to determine the ability of intravenous dexamethasone in decreasing the incidence, severity and the need for treatment for post spinal shivering. MATERIALS AND METHODS: We recruited a total of 72 patients who required spinal anaesthesia and randomised them to either dexamethasone $0.1 \mathrm{mg} / \mathrm{kg}$ (maximum of $8 \mathrm{mg}$ ) or normal saline (placebo). The subjects' tympanic membrane temperatures (TMT), mean arterial pressures (MAP) and shivering scores were observed at regular intervals up to 2-hours post-spinal or till end of surgery (minimum 30 minutes post spinal). An intravenous pethidine $25 \mathrm{mg}$ were given as rescue therapy for Grade 3 and 4 shivering. RESULTS: There were consistent and comparable drop in TMT and MAP after spinal anaesthesia in both groups, except at 15 minutes whereby dexamethasone group demonstrated significantly higher temperatures than saline group $(\mathrm{p}=0.04)$. There was significantly less incidence of visible muscular shivering (Grade 2 to Grade 4$)$ in the dexamethasone group as compared to placebo group ( $p=0.003$ ). The highest grade of shivering observed for dexamethasone and saline group was 2 and 3 respectively. A total of 2 subjects from saline group required rescue therapy. CONCLUSION: Dexamethasone can potentially mitigate the reduction in core body temperature, especially at 15 -minutes post spinal with significantly less visible muscular shivering.
\end{abstract}

\section{INTRODUCTION}

Post spinal shivering is a common occurrence with a median incidence of $50 \%$ in patients who had undergone central neuraxial anaesthesia. ${ }^{1}$ Although shivering is commonly seen in hypothermia, it can also be seen in normothermic patients during the perioperative period. ${ }^{2}$ Shivering occurs as a physiological response to cold, whereas a peripheral vasoconstriction is the primary attempt to preserve heat. ${ }^{2}$ In general, shivering can be attributed to intraoperative heat loss, increased sympathetic tone, pain, and systemic release of pyrogens. ${ }^{3,4}$ However, the exact mechanism for post spinal shivering itself is poorly understood. The cause of spinal shivering is widely attributed to impaired thermoregulation by inhibition of tonic vasoconstriction, ${ }^{5}$ from below the level of block and redistribution of core heat from the trunk to the peripheries, ${ }^{6}$ causing patients prone to hypothermia and consequently shivering.
Generally, shivering causes significant discomfort to patient, worsen wound pain and increases the incidence of bleeding or infection. ${ }^{4}$ Shivering causes sympathetic stimulation manifested as tachycardia and hypertension, thus aggravating certain medical conditions such as patients with ischaemic heart disease. ${ }^{3}$ Shivering also increases tissue oxygen demands, elevates cardiac output and both carbon dioxide production and consumption as well as intraocular and intracranial pressures. ${ }^{7,8}$

To date, there is currently no single best treatment or prevention of post spinal shivering despite multiple strategies proposed in the past which include nonpharmacological method such as using forced air warming device and pharmacological treatment with opioids, $\alpha 2$ agonists, magnesium sulphate, physostigmine and $5-\mathrm{HT}_{3}$ 
antagonists. ${ }^{9}, 10$ Intravenous (IV) pethidine is considered the most effective and widely used drug to treat post spinal shivering. ${ }^{9-11}$ The postulated effect of pethidine on post spinal shivering is via its agonist actions on $\mu$ and $x$ receptors and eventual reduction in shivering threshold temperatures. ${ }^{10}$ However, the optimal dose of pethidine in preventing shivering is limited by side effects such as respiratory depression, sedation, nausea, vomiting, pruritus and urinary retention. Davoudi et al. (2007) reported that a small dose of intrathecal pethidine is effective in decreasing shivering associated with spinal anaesthesia. ${ }^{2}$ However, intrathecal opioid administration is relatively more invasive and carries risk of opioid side effects ${ }^{13}$

Dexamethasone has been used in mitigating post general anaesthesia shivering as the mechanism behind shivering in general anaesthesia is almost similar to that in spinal anaesthesia.4,14 Besides being commonly used in prevention of post-operative nausea and vomiting, dexamethasone is also a powerful anti-inflammatory and analgesia agent. Yared et al. (1998) found that IV dexamethasone reduced the incidence of shivering after cardiac surgery and attributed it to modulation of the immune and inflammatory response besides decreasing the gradient between core and skin temperatures.4,14 Solhpour et al. (2016) found that IV dexamethasone $0.1 \mathrm{mg} / \mathrm{kg}$ combined with pethidine $0.2 \mathrm{mg}$ / $\mathrm{kg}$ is more effective than pethidine alone in prevention of post spinal shivering, but comes with opioid side effects. ${ }^{15}$ It is believed that dexamethasone relieves inflammation and pain by attenuating release of inflammatory mediators, blocking transmission of nociceptive C-fibres and suppressing ectopic neural discharge. ${ }^{16}$ Hence, its inhibition on the inflammatory mediators' release and central inhibitory effect on thermoregulatory centre may contribute to its role in preventing post spinal shivering. We conducted this study with the aim of examining the effect of intravenous dexamethasone on the incidence, severity and need for treatment of post spinal shivering.

\section{MATERIALS AND METHODS}

This prospective, double-blind, randomised controlled study was conducted in Universiti Kebangsaan Malaysia Medical Centre (UKMMC) from June 2019 to February 2020 following the approval from the Research Committee of Department of Anaesthesiology \& Intensive Care, UKMMC as well as the Medical Research \& Ethics Committee, UKMMC (FF-2019-202).

\section{Study population}

Patients with American Society of Anaesthesiologists (ASA) class I or II aged 18 years and above scheduled for surgery IMJM Volume 20 No.4, October 2021 under spinal anaesthesia, with duration of surgery exceeding 30 minutes were recruited for this study. Exclusion criteria included contraindication to spinal anaesthesia, known allergy to study medication, long-term oral corticosteroid therapy, height below $145 \mathrm{~cm}$, body mass index (BMI) of more than 35 $\mathrm{kg} / \mathrm{m}^{2}$, active ongoing sepsis, preoperative temperature of more than $38^{\circ} \mathrm{C}$ or less than $35^{\circ} \mathrm{C}$, diagnosis of Parkinson's disease, hypo- or hyperthyroidism, parturient and intraoperative blood transfusion. Written informed consent were obtained from patients recruited into the study. Patients who needed conversion to general anaesthesia within 2 hours of spinal anaesthesia were dropped out of this study.

\section{Study methodology}

Patients were randomly assigned into two groups via computer-generated randomised numbers (QuickCalcs by GraphPad). Group 1 patients received $0.1 \mathrm{mg} / \mathrm{kg}$ (maximum $8 \mathrm{mg}$ ) of IV dexamethasone (CCM Duopharma ${ }^{\circledR}$ Penatone ${ }^{\circledR}$ injection) diluted to a volume of $10 \mathrm{ml}$. Group 2 patients received $10 \mathrm{ml}$ of IV normal saline $(0.9 \% \mathrm{NaCl})$ as placebo. Study medication was prepared by the investigator while the attending anaesthetist observing the patient was blinded to the drug.

All patients did not receive any sedative pre-medication. On arrival in the operating theatre, baseline tympanic membrane temperatures (TMT) of the patients were taken using Omron ${ }^{\circledR}$ ear thermometer TH839S. The study drug was then administered as a slow IV bolus at least 30 minutes before the establishment of spinal anaesthesia.

All spinal anaesthesia procedures were performed under aseptic techniques at the L3/4 or L4/5 intervertebral spaces. Once free flow of cerebrospinal fluid was obtained, $12.5 \mathrm{mg}$ $(2.5 \mathrm{ml})$ of $0.5 \%$ hyperbaric bupivacaine together with $25 \mathrm{mcg}$ $(0.5 \mathrm{ml})$ of fentanyl were injected into the subarachnoid space (total injectate volume of $3.0 \mathrm{ml}$ ). Standard monitoring with a three-lead electrocardiogram (ECG), non-invasive blood pressure (NIBP) monitor and pulse oximetry were applied. All patients received warmed intravenous fluids of either $0.9 \%$ $\mathrm{NaCl}$ or lactated Ringer's solution which were stored in a warming cabinet with temperature maintained at $32^{\circ} \mathrm{C}$. They were also given supplementary oxygen by nasal cannula at 3 $\mathrm{L} / \mathrm{min}$. Intraoperatively, patients' upper body were covered with a blanket and forced air warming therapy at $38^{\circ} \mathrm{C}$ were applied. The ambient temperature in the operating room was maintained at $20^{\circ} \mathrm{C}-22^{\circ} \mathrm{C}$ along with constant humidity.

Apart from standard monitoring of heart rate, oxygen saturation and respiratory rate, mean arterial pressure (MAP) were recorded every 5 minutes. The first TMT was taken at 5 minutes post spinal and subsequently at 15-minutes interval 
until the end of surgery or a maximum of 2 hours post-spinal. Shivering intensity was evaluated via a 5 -point scale similar to that validated by Crossley and Mahajan ${ }^{17}$ to grade shivering, whereby $0=$ no shivering; $1=$ peripheral vasoconstriction or piloerection but no visible muscular shivering; 2 = visible muscular activity in only 1 muscle group; 3 = visible muscular activity in more than 1 muscle group but not generalised; and 4 = shivering involving the whole body. Visible muscular shivering was defined as grade 2 to 4 . Shivering intensity scoring were recorded at 5-minute intervals until the end of surgery (minimum of 30 minutes post spinal) or a maximum of 2 hours post spinal. IV pethidine $25 \mathrm{mg}$ was to be administered if a grade 3 or 4 shivering occurred at any interval following spinal anaesthesia. If shivering reappeared, subjects were treated with an additional dose of IV pethidine $25 \mathrm{mg}$.

Any presence of side effects after spinal anaesthesia that required treatment including hypotension, bradycardia, nausea, vomiting or pruritus were noted and managed accordingly.

\section{STATISTICAL ANALYSIS}

The sample size was calculated using NCSS Power Analysis and Sample Size Software (PASS) 11 to determine the association of treatment group (i.e. dexamethasone and saline) and shivering grades (i.e. grade 0 to 4 ) among patients undergoing spinal anaesthesia. Sample size was calculated based on previous study with expected reduction in shivering by $30 \%$ (saline versus dexamethasone). A total of 65 patients were needed to achieve a power of $90 \%$ with alpha value of 0.05 .18 With anticipation of $10 \%$ drop-out rate, total sample required was 72 , with 36 subjects per group.

All data analyses were performed using SPSS for Windows version 22.0 (IBM Corp, Armonk, NY, USA). Results were presented as mean \pm standard deviation or frequency (percentages) where appropriate. Chi-square test was used for categorical variables, while continuous variables were compared across the two groups using independent t- test if the data was normally distributed and Mann-Whitney $U$ test if the data were not normally distributed. A $p$ value $<0.05$ was considered as statistically significant.

\section{RESULTS}

A total of seventy-two patients were recruited into this study with no drop-out. Table I showed patients' demographic data, surgical discipline and surgical duration which were found to be comparable between both groups.
Table I: Demographic data, surgical discipline and duration of surgery. Values are expressed in mean \pm standard deviation or number (percentage) where appropriate.

\begin{tabular}{|c|c|c|c|}
\hline & $\begin{array}{c}\text { Group 1 } \\
\text { [Dexamethasone] } \\
(\mathrm{n}=36)\end{array}$ & $\begin{array}{c}\text { Group 2 } \\
\text { [Saline] } \\
(\mathrm{n}=36)\end{array}$ & $\begin{array}{c}p \\
\text { value }\end{array}$ \\
\hline Age (years) & $50.97 \pm 19.57$ & $55.86 \pm 14.28$ & 0.23 \\
\hline $\begin{array}{l}\text { Gender } \\
\text { Male } \\
\text { Female }\end{array}$ & $\begin{array}{l}23(56.1) \\
13(41.9)\end{array}$ & $\begin{array}{l}18(43.9) \\
18(58.1)\end{array}$ & 0.23 \\
\hline $\mathrm{BMI}\left(\mathrm{kg} / \mathrm{m}^{2}\right)$ & $26.32 \pm 5.10$ & $26.76 \pm 4.70$ & 0.70 \\
\hline $\mathrm{BSA}\left(\mathrm{m}^{2}\right)$ & $1.82 \pm 0.21$ & $1.76 \pm 0.21$ & 0.26 \\
\hline $\begin{array}{l}\text { ASA categories } \\
\text { I } \\
\text { II }\end{array}$ & $\begin{array}{c}9(64.3) \\
27(46.6)\end{array}$ & $\begin{array}{r}5(35.7) \\
31(53.4)\end{array}$ & 0.23 \\
\hline $\begin{array}{l}\text { Discipline } \\
\text { Lower limb } \\
\text { surgery } \\
\quad \text { Orthopaedics }\end{array}$ & $20(55.5)$ & $25(69.4)$ & 0.22 \\
\hline $\begin{array}{l}\text { Lower abdominal } \\
\text { surgery } \\
\text { Gynaecology } \\
\text { General Surgery } \\
\text { Urology }\end{array}$ & $\begin{array}{l}4(11.1) \\
7(19.4) \\
5(13.9)\end{array}$ & $\begin{array}{l}7(19.4) \\
3(8.3) \\
1(2.8)\end{array}$ & \\
\hline $\begin{array}{l}\text { Total lower } \\
\text { abdominal surgery }\end{array}$ & $16(44.4)$ & $11(30.6)$ & \\
\hline $\begin{array}{l}\text { Duration of surgery } \\
\text { (min) }\end{array}$ & $69.17 \pm 37.83$ & $55.69 \pm 31.17$ & 0.10 \\
\hline
\end{tabular}

We identified incidence of shivering by documenting each patient's highest recorded grade of shivering throughout surgery and then grouped it as Grade 0 (no shivering) versus Grade 1 to 4 (shivering). We found no significant difference when we compared the incidence of shivering in both groups (Table II).

Table II: Comparison of incidence of shivering in both groups. Values are expressed in number (percentage).

\begin{tabular}{lccc}
\hline & $\begin{array}{c}\text { Group 1 } \\
\text { [Dexamethasone] } \\
(\mathrm{n}=36)\end{array}$ & $\begin{array}{c}\text { Group 2 } \\
\text { [Saline] } \\
(\mathrm{n}=36)\end{array}$ & $\boldsymbol{p}$ value \\
\hline $\begin{array}{l}\text { No shivering } \\
(\text { Grade })\end{array}$ & $16(44.4)$ & $18(50.0)$ & \\
$\begin{array}{l}\text { Shivering } \\
\text { (Grades 1 to 4) }\end{array}$ & $20(55.6)$ & $18(50.0)$ & 0.64 \\
\hline
\end{tabular}

We then sub-analysed the presence of shivering in both groups (Table III) by identifying non-visible muscular shivering (Grade 1) against visible muscular shivering (Grades 2,3 or 4) and we found significantly less patients in dexamethasone group having visible muscular shivering compared to the placebo group ( $p=0.003$ ).

As shown in Figure 1, the mean TMT were higher at all time intervals for dexamethasone group compared to saline group although they were not statistically significant except for 15 minutes post-spinal $(p=0.04)$. 
Table III: Comparison of presence of non-visible muscular shivering versus visible muscular shivering in both groups. Values are expressed in number (percentage).

\begin{tabular}{|c|c|c|c|}
\hline & $\begin{array}{c}\text { Group 1 } \\
\text { [Dexamethasone] } \\
(\mathrm{n}=20)\end{array}$ & $\begin{array}{c}\text { Group 2 } \\
\text { [Saline] } \\
(\mathrm{n}=18)\end{array}$ & $\begin{array}{c}p \\
\text { value }\end{array}$ \\
\hline $\begin{array}{l}\text { Non-visible } \\
\text { muscular } \\
\text { shivering }\end{array}$ & \multirow[t]{2}{*}{$13(65.0)$} & \multirow[t]{2}{*}{$3(16.7)$} & \\
\hline (Grade 1) & & & 0.003 \\
\hline $\begin{array}{l}\text { Visible } \\
\text { muscular } \\
\text { shivering }\end{array}$ & \multirow[t]{2}{*}{$7(35.0)$} & \multirow[t]{2}{*}{15 (83.3) } & \\
\hline $\begin{array}{c}\text { (Grades 2,3 } \\
\text { and 4) }\end{array}$ & & & \\
\hline
\end{tabular}

The shivering grades between dexamethasone and saline groups at 5 -minute intervals were shown in Figure 2 and both were statistically comparable at all time intervals until 70 minutes post-spinal. From 75 minutes until 120 minutes post -spinal, there was no shivering recorded from both groups. Highest grade of shivering for dexamethasone group was 2 while saline group recorded maximum grade 3 shivering. Shivering post spinal was noted to occur as early as 5 minutes post spinal in both groups.

Figure 1: Mean TMT trend in both groups at different time intervals. Values are expressed in mean \pm standard deviation.

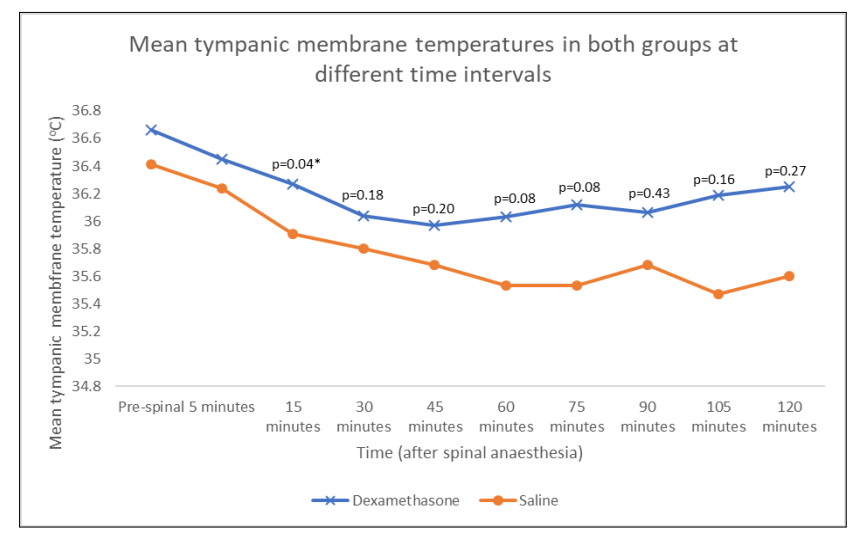

$* p<0.05$ which is statistically significant

There were only two subjects who had Grade 3 shivering and needed a single dose of pethidine, and both were in the saline group. None of the patients in either group had Grade 4 shivering. There was no significant difference between both groups for incidence of Grade 3 or 4 shivering $(p=0.49)$ and pethidine usage $(p=0.49)$.

The reduction in MAP from baseline following spinal anaesthesia were noted at all time intervals and comparable between both groups.

Two patients from each group had hypotension requiring treatment with ephedrine boluses. Incidence of bradycardia, nausea, vomiting or pruritus were not reported in either

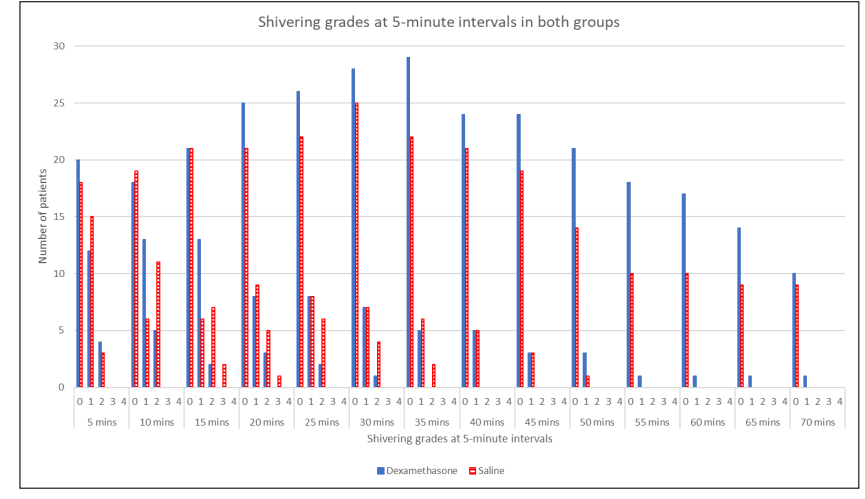

Figure 2: Shivering grades in both groups at 5-minute intervals.

group. There was no difference in both groups in terms of the side effects mentioned.

\section{DISCUSSION}

Many theories have been proposed for the cause of shivering occurring during spinal anaesthesia, but its exact pathophysiology is still unknown. Suggested mechanisms of shivering include the impairment of central thermoregulatory centre in the brain leading to reduction in vasoconstriction and shivering thresholds, redistribution of body heat from the core to the peripheral compartments, and dissipation of heat from body surfaces to the environment due to loss of thermoregulatory vasoconstriction below the level of spinal block. $5,6,19$

Several studies observed an increase of gradient between skin and core temperatures in both general as well as spinal anaesthesia. ${ }^{1,9,16}$ In our study, we measured TMT as they correlate well with core body temperature. ${ }^{20} \mathrm{We}$ noted that there was a concordant drop in the mean TMT and MAP of patients, with the most substantial fall occurring in the first 15 minutes post-spinal. The drop in MAP observed post spinal were expected in both groups and were comparable at all time intervals. Interestingly, the mean TMT of patients in the dexamethasone group were found to be consistently higher at all time intervals post spinal compared to the placebo group, although significant difference was only seen at 15-minutes post spinal. The post spinal vasodilatory effects likely contributed to the fall in MAP which also coincided with the redistribution of core body temperature to the peripheries. This may explain why the mean TMT fell the most during the first 15 minutes, with a greater temperature fall observed in the placebo group. During subsequent time intervals, the rate of temperature fall reduced as temperature equilibrated due to heat gain from active warming. This showed that dexamethasone has the potential to mitigate the fall in core body temperature, especially in the first 15-minutes post spinal. This unique potential of dexamethasone was seen in multiple other studies before this as well.4,14,16 
In our study the incidence of shivering after spinal anaesthesia was comparable in both groups, though there were studies that showed reduced incidence of shivering with dexamethasone alone. ${ }^{14,18}$ However, it must be noted that shivering in most clinical setting can be either visible or nonvisible, and patients with non-visible Grade 1 shivering are often as comfortable as those with no shivering. As Grade 2 shivering sets in as a physiologic response to cold, peripheral vasoconstriction and piloerection (Grade 1) would often be missed by clinician compared to the visibly evident grade of muscular shivering (Grade 2 and above) unless one looks very hard for it. To date, there has been no study involving dexamethasone in post spinal shivering that compared visible and non-visible grade of shivering. Hence, when we grouped our shivering grades according to visible muscular shivering (Grade 2, 3 and 4) and non-visible muscular shivering (Grade 1 ), we noted significantly less visible muscular shivering in the dexamethasone group compared to the saline group. We also found that all patients in dexamethasone group with visible muscular shivering recorded only a maximum of Grade 2 shivering, while the placebo group reported two patients with Grade 3 shivering that required pethidine. This demonstrated that dexamethasone was able to reduce the overall incidence of visible shivering in patients given spinal anaesthesia, likely via its ability in maintaining core temperature.

There were a few limitations in this study. Our study was limited to the time spent in the operating room for only the duration of the surgery post spinal. We were unable to evaluate shivering intensity after end of surgery as the transfer of patients to the recovery room or ward causes a change in the ambient environment and this may confound the shivering grade. We also did not measure TMT at 5-minute intervals as this might be uncomfortable for patients to have their ears probed too frequently for temperature measurement. We noted that shivering occurred as early as 5 minutes post spinal in both groups and the first TMT taken was 5 minutes after spinal. Perhaps a more frequent measurement of TMT in the first 5 minutes may paint a more accurate picture on the onset of shivering and dexamethasone's role in preservation of core body temperature post spinal.

\section{CONCLUSION}

We conclude that IV dexamethasone has the potential to reduce the drop in core body temperature, especially at 15 minutes post spinal and it can reduce the incidence of clinically significant visible grade of shivering after spinal anaesthesia.

\section{CONFLICTS OF INTEREST}

The authors declare no conflicts of interest.

\section{FUNDING}

The authors have no sources of funding to declare for this manuscript.

\section{ACKNOWLEDGEMENTS}

The authors would like to thank Puan Qurratu' Aini Binti Musthafa for her assistance in the statistical analysis of this study

\section{CLINICAL TRIAL REGISTRATION NUMBER}

This study is registered under the Research Committee of Department of Anaesthesiology \& Intensive Care, UKMMC as well as the Medical Research \& Ethics Committee, UKMMC (FF-2019-202).

\section{REFERENCES}

1. Honarmand A, Safavi MR. Comparison of prophylactic use of midazolam, ketamine, and ketamine plus midazolam for prevention of shivering during regional anaesthesia: a randomized double-blind placebocontrolled trial. Br J Anaesth 2008; 101(4)557-562.

2. Maria BL. Postanaesthestic shivering - from pathophysiology to prevention. Rom J Anaesth Intensive Care 2018; 25(1):73-81

3. Imrie MM, Hall GM. Body temperature and anaesthesia. BrJ Anaesth 1990; 64:346-354.

4. Yared JP, Starr NJ, Hoffmann-Hogg L et al. Dexamethasone decreases the incidence of shivering after cardiac surgery: a randomized, double-blind, placebo-controlled study. Anesth Analg 1998; 87(4):795799.

5. Simon E. Temperature regulation: The spinal cord as a site of extrahypothalamic thermoregulatory functions. Rev Physiol Biochem Pharmacol 1974; 71:1-76.

6. Matsukawa T, Sessler DI, Christensen R et al. Heat flow and distribution during epidural anesthesia. Anesthesiology 1995; 83(5):961-967.

7. McDowall DG. Influence of anaesthetic drugs and techniques in ICP. In: Gordon E. A Basis and Practice of Neuroanaesthesia. Amsterdam: Excerpta Medica; 1981.173 $-253$.

8. Bilotta F, Pietropaoli P, La Rosa I et al. Effects of shivering prevention on haemodynamic and metabolic demands in hypothermic postoperative neurosurgical patients. Anaesthesia 2001; 56(6):514-519. 
9. Kelsaka E, Baris S, Kerakaya D et al. Comparison of ondansetron and meperidine for prevention of shivering in patients undergoing spinal anesthesia. Reg Anesth Pain Med 2006; 31(1):40-45.

10. Alfonsi P. Postanaesthetic shivering: epidemiology, pathophysiology, and approaches to prevention and management. Drugs 2001; 61(15):2193-2205.

11. Wang JJ, Ho ST, Chun S et al. A comparison among nalbuphine, meperidine and placebo for treating postanesthetic shivering. Anesth Analg 1999; 88(3):686689.

12. Davoudi M, Mousavi-Bahar SH, Farhanchi A. Intrathecal meperidine for prevention of shivering during transurethral resection of prostate. Urol J 2007; 4 (4):212-216.

13. Bharti N, Batra KY, Negi LS. Efficacy of intrathecal midazolam versus fentanyl for endoscopic urology surgery. South Afr J Anaesth Analg 2015; 21(2):13-16.

14. Entezariasl M, Isazadehfar K. Dexamethasone for prevention of postoperative shivering: a randomized double-blind comparison with pethidine. Int J Prev Med 2013; 4(7):818-824.

15. Solhpour A, Jafari A, Hashemi M et al. A comparison of prophylactic use of meperidine, meperidine plus dexamethasone, and ketamine plus midazolam for preventing of shivering during spinal anesthesia: a randomized, double-blind, placebo-controlled study. $J$ Clin Anesth 2016; 34:128-135.

16. Benzon HT. Epidural steroids. In: Raj PP. Pain Medicine, A Comprehensive Review. St. Louis: Mosby,1999; 259-263.

17. Crossley AWA, Mahajan RP. The intensity of postoperative shivering is unrelated to axillary temperature. Anaesthesia 1994; 49:205-207.

18. El Bakry AEAA, Ibrahim ES. Prophylactic dexamethasone or pethidine for the prevention of postoperative shivering during transurethral resection of prostate under spinal anaesthesia. Ain-Shams J Anesthesiol 2016; 09:349-352.

19. Ozaki M, Kurz A, Sessler DI et al. Thermoregulatory thresholds during spinal and epidural anesthesia. Anesthesiology 1994; 81:282-288.

20. Childs C, Harrison R, Hodkinson C. Tympanic membrane temperature as a measure of core temperature. Arch Dis Child 1999; 80:262-266. 